\title{
EXPERIMENTAL STUDY OF CONCRETE-FILLED STEEL TUBULAR ARCHES WITH CORRUGATED STEEL WEBS
}

\author{
Jing $\mathrm{Gao}^{1}$, Jiazhan $\mathrm{Su}^{2}$, Yong $\mathrm{Xia}^{3, *}$ and Baochun $\mathrm{Chen}^{4}$ \\ ${ }^{1}$ Associate professor, Department of Civil Engineering, Xiamen University, China \\ ${ }^{2}$ Research student, Department of Civil and Environmental Engineering, \\ The Hong Kong Polytechnic University, Hong Kong \\ ${ }^{3}$ Associate professor, Department of Civil and Environmental Engineering, \\ The Hong Kong Polytechnic University, Hong Kong \\ ${ }^{4}$ Professor, College of Civil Engineering, Fuzhou University, China \\ *(Corresponding author: E-mail: ceyxia@polyu.edu.hk)
}

Received: 20 March 2013; Revised: 12 June 2013; Accepted: 17 October 2013

\begin{abstract}
Concrete-filled steel tubular (CFST) arches with corrugated steel web (CSW) are a new developing type of arches, which combine the high strength of CFST and good shearing resistance of CSW. This paper studies the behaviour of CFST arches with CSW (or CFST-CSW arches) under in-plane and out-of-plane loading conditions. A series of experiments was conducted. The displacement and strain of CFST-CSW arch models under different loading schemes were measured. These experiments enabled the direct assessment of the load-deflection and failure mode of the CFST-CSW arches. The effectiveness of this new arch type verified by comparison of a reinforced concrete arch model with CSW in terms of the ultimate load and failure mode.
\end{abstract}

Keywords: Concrete-filled steel tube (CFST), Corrugated steel web (CSW), Arch, Load-carrying capacity, Failure mode

\section{INTRODUCTION}

A concrete-filled steel tube (CFST), which consists of a thin-walled steel tube and a concrete core, fully utilizes the geometric efficiency and mechanical characteristics of both components. The concrete infill is confined by the steel tube, resulting in a triaxial state of compression and increasing the strength and ductility of the concrete. On the other hand, the concrete core improves the local and global buckling capacity of the steel tube (Zhao et al. [1]). Given these merits, CFST has been widely used in columns, piers, and arches where compression is dominant (Zhong [2], Bradford et al. [3], Roeder et al. [4], Pi et al. [5]).

To enhance the bending stiffness and stability, laced CFST structures (named as truss rib in CFST arches), which utilize two or more CFST members tied together by either laced steel hollow tubular members or battened members, are used as columns or arches (Bode [6], Chen and Wang [7]). More than 200 CFST arch bridges have been constructed in China because of their low fabrication costs and fast erection. Among them, 33 bridges with spans greater than $200 \mathrm{~m}$ adopt CFST truss ribs (Chen and Wang [7]). One example is the $460 \mathrm{~m}$ span Wuxia Yangtze River Bridge, which is the longest CFST arch bridge in the world (Mu et al. [8]). However, for most of the long span CFST arches with quite slender ribs, buckling is one of the major concerns in the design. Moreover, there is no prescriptive code or guidance available for the strength design of CFST arches. Research of laced CFST structures is also limited. Ou et al. [9] performed an experimental study of the ultimate load of the laced CFST column. They found that the shear effect resulting from laced members or battened members reduced the ultimate load when the column is slender. Experimental investigation by Chen and Huang [10] showed that when the CFST truss girder was subjected to bending, the failure of joints considerably reduces the ultimate load. Furthermore, the welding intersection between the laced tube (or tubular web) and chords generally governs the fatigue life, which is also critical in construction and quality control. 
In recent years, the corrugated steel web $(\mathrm{CSW})$ has been commonly employed in steel girders and prestressed concrete girders because CSW not only enhances shear stability, but also reduces the self-weight (dead load) (Elgaaly et al. [11], Johnson and Cafolla [12], Chan et al. [13], Li et al. [14]). The CFST structure with CSW was proposed, motivated by the Val de Maupre Viaduct, in which the steel tubular web members in a truss system were substituted for CSW without tube-to-tube welding intersection (Brozzetti [15], Chen and Wang [16], Wei et al. [17]).

The combination of the CFST and CSW forms a new structure component (briefly referred to as CFST-CSW), whereas some new issues such as buckling of the CSW, ultimate load-carrying capacity, and failure modes under different loading conditions have not been sufficiently studied. Gao and Chen [18] carried out experiments on a CFST-CSW beam under bending. The results indicated that the flexural rigidity and ultimate load-carrying capacity of the CFST-CSW beam considerably improved compared with the CFST truss beam. Furthermore, Gao and Chen [19] conducted experiments on a CFST-CSW column. The results demonstrated that the mechanical behavior of the CFST-CSW column is similar to the CFST laced columns. Compared with CFST, CFST-CSW columns have a small shear deformation, indicating that CSWs have good shear resistance.

This paper extends the previous studies on CFST-CSW structures and applies it to arches. Three CFST-CSW arch models were tested in the laboratory, in which in-plane and out-of-plane loadings were applied. The structural responses, including displacement and strain under different loading conditions, were measured and analyzed. The ultimate load-carrying capacity and the failure mode of the CFST-CSW arches were investigated, as well.

\section{EXPERIMENTAL INVESTIGATION}

\subsection{Physical Models}

Three CFST-CSW arches with identical geometric dimensions but under different loading schemes were designed and tested. The first two models, ACSW-1 and ACSW-2, were tested under in-plane loading with different vertical loading schemes. The former was loaded symmetrically at $5 / 12$ and $7 / 12$ of the span, whereas the latter was loaded at $2 / 3$ and $5 / 6$ of the span, as shown in Figure 1(a) and Figure 1(b), respectively. During the test of the third arch model, ACSW-3, five in-plane vertical loads were applied simultaneously with a lateral load at the arch crown. The magnitude of the lateral load $(P / 10)$ was $2 \%$ of the total vertical loads $(5 P)$, as shown in Figure 1(c).

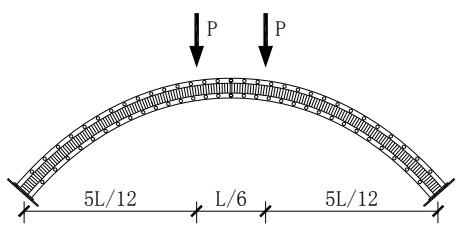

(a) ACSW-1

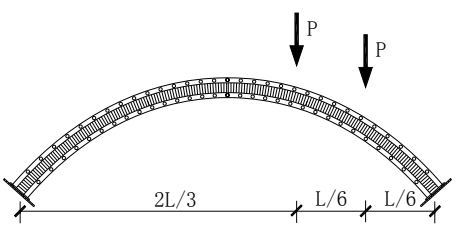

(b) ACSW-2

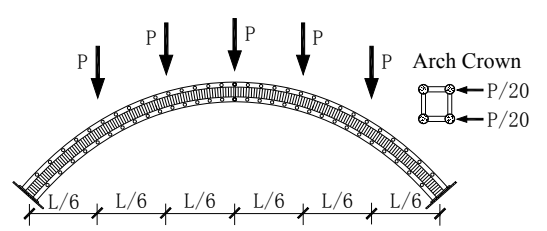

(c) ACSW-3

Figure 1. Arch Models and Loading

One typical arch model is shown in Figure 2. The arch has a parabolic profile. It has a rise of 1.556 $\mathrm{m}$ and a span of $6.223 \mathrm{~m}$ (measured from the center of both springings), giving a rise to span ratio of 1/4. Its uniform cross section is $300 \mathrm{~mm}$ deep and $275 \mathrm{~mm}$ wide. The arch consists of four CFSTs connected by two continuous vertical CSWs and two series of transverse bracings. Each tubular chord is $75 \mathrm{~mm}$ in diameter with a thickness of $1.8 \mathrm{~mm}$. The $2 \mathrm{~mm}$ thick CSW was welded continuously to the top sides of the bottom tubular chords and bottom sides of the upper tubular 
chords along the arch axis. The geometrical size of the CSW is shown in Figure 2(c). The transverse bracings are steel tubes with $40 \mathrm{~mm}$ in diameter and $2 \mathrm{~mm}$ in thickness, and welded at a uniform spacing of $195 \mathrm{~mm}$ in both top and bottom chords. The average yield stress of the steel was tested to be $335 \mathrm{MPa}$, and the average ultimate strength was $417 \mathrm{MPa}$. The Young's elastic modulus of steel was $210 \mathrm{GPa}$. The average ultimate strength of concrete was $44 \mathrm{MPa}$ with the Young's modulus of $34.7 \mathrm{GPa}$.

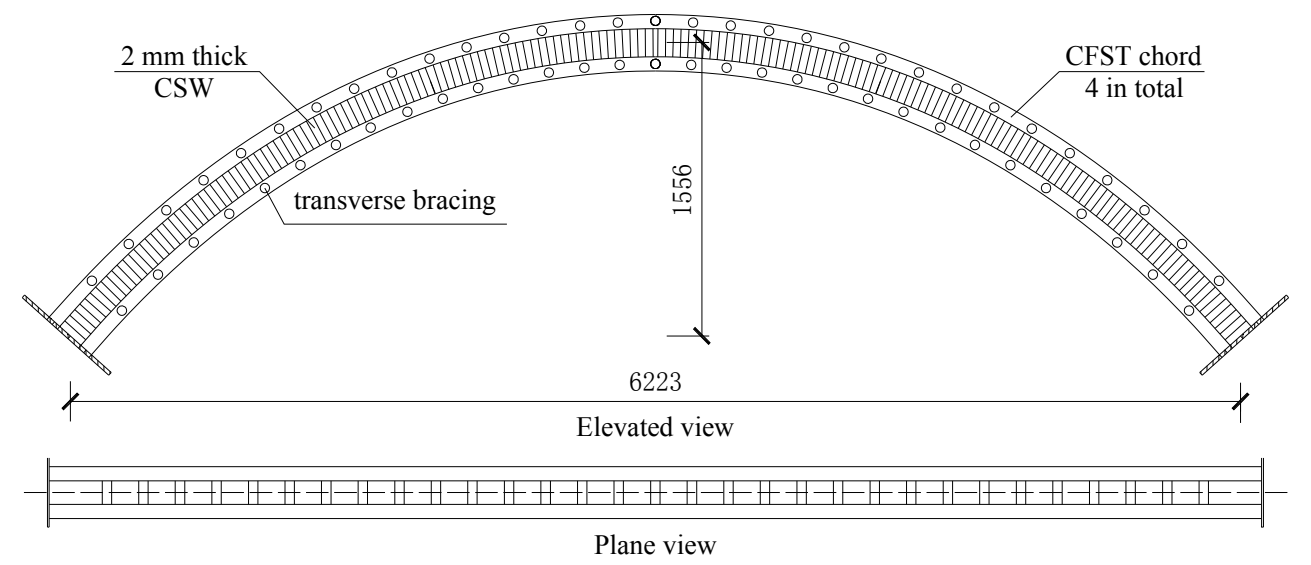

(a) Elevation

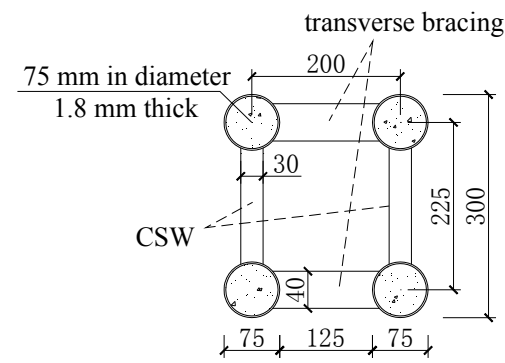

(b) Cross-section

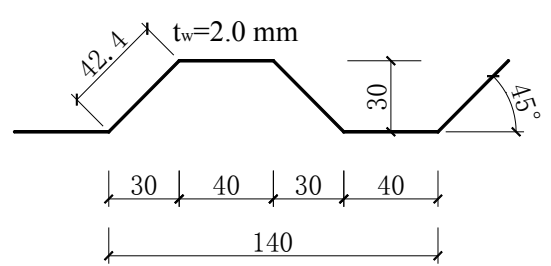

(c) CSW

Figure 2. Configuration of the Arch Model (unit: mm)

The arch models were fixed on two stiffened steel pedestals at ends. Supports were made up of triangular steel plates placed on a reinforced concrete block anchored to the ground. The supports restricted the horizontal displacement and rotation of the arch springing, simulating the fixed support conditions.

The load step was designed according to the preliminary analysis of the arch. At each load step, the loading was kept constant for at least three minutes to stabilize the response. The load $\mathrm{P}$ was applied gradually using hydraulic jacks on loading frames. The load jacks were driven by several oil-pumps that were mechanically coupled to ensure synchronization. The operating capacity of each jack was approximately $600 \mathrm{kN}$. Two overhead braced steel frames provided the required support for the jacks. Load cells, one at each jack location, were used to measure the applied loads. The magnitude of the applied loads was determined from the predefined nominal strains. The minimum load per jack was $5 \mathrm{kN}$, which corresponds to a minimum nominal strain of approximately $30 \mu \varepsilon$. Additionally, at the end of each jack, a ball-and-socket joint was provided to allow for unrestrained longitudinal displacement at the loading point. 


\section{$2.2 \quad$ Instrumentation}

The positioning of strain gauges and linear voltage displacement transducers (LVDT's) for the models is illustrated in Figure 3. A total number of 234 or 13 sets of electronic resistance strain gauges were positioned at L/12 intervals along the arch (sections $a$ to $g$ and $a$ ' to $f^{\prime}$ ). Three types of strain gauges were used. Uniaxial strain gauges were used in the longitudinal direction for the connection of the CSWs and chords (points 5, 6, 5', and 6'), biaxial strain gauges were used on the chord to record longitudinal strains and circumferential strain (points 1 to 4 and 1' to 4'), and strain gauge rosettes were installed on the CSWs to measure the shear (points 7 to 9 and 7' to 9'). For ACSW-1, seven LVDT's were attached to the bottom chord of the arch at positions L/12, L/4, 5L/12 and the crown (i.e., points $A, C, E, F$ and their symmetric locations), to measure the in-plane deflections of the arch. For ACSW-2, the LVDT's were installed at points $A, B, D, F$ and their symmetric locations of the bottom chord. For ACSW-3, five LVDT's were attached to the bottom chord of the arch at points $B, D, F$ and their symmetric locations to measure the vertical deflections, and five more LVDT's were attached to the same positions to measure the lateral deflections. A commercial data acquisition system DH3816 was used to record the readings of the strain gauges, LVDT's, and load cells.
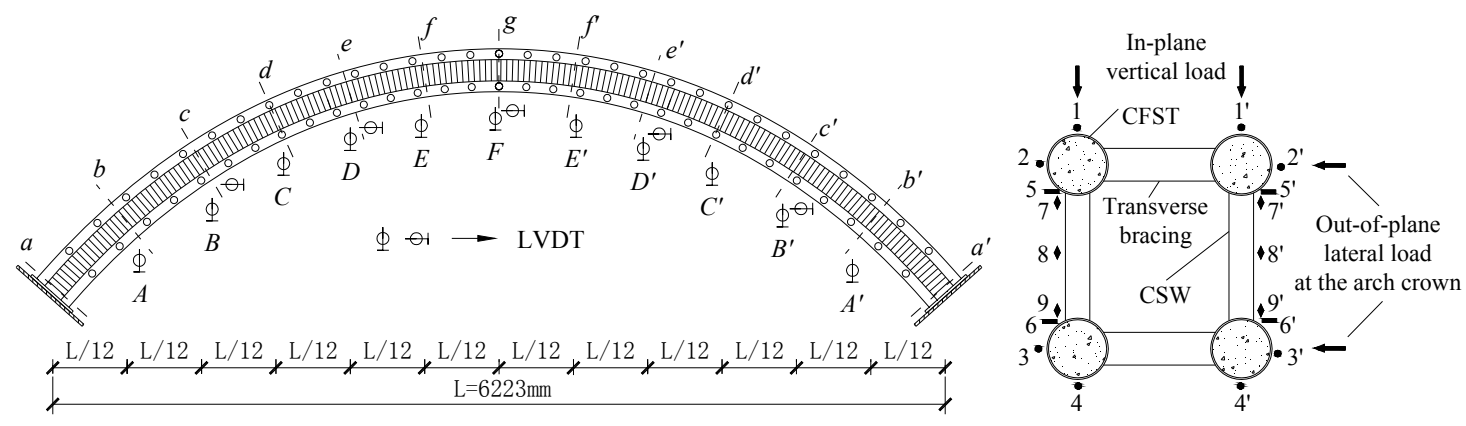

Figure 3. Positions of Strain Gauges and LVDT's in One Model

\subsection{Testing Procedure and Observations}

All three models were loaded to about $20 \%$ of the ultimate load to check the setup and instrumentation before the formal test began. In the formal test, the arch was loaded progressively in load increments of $10 \mathrm{kN}$ until failure in the elastic phase, and $5 \mathrm{kN}$ after entering the elastic-plastic phase.

Figure 4(a) shows the deformed shapes of ACSW-1 under the ultimate load. The local web buckling occurred near the quarter span (Region A in the Figure) involving at least several folds in the webs. As a result, the plastic deformation was distributed along the arch. Particularly, the buckling waves, extending over parts of the inclined folds as well as the longitudinal folds, had similar sizes and angles of inclination with respect to the arch axis. The buckled web after the load drop is shown in Figure 4(b). As ACSW-1 was loaded further, more folds in CSWs buckled near the quarter span, and the tubes of the chords near the arch springings wrinkled. 


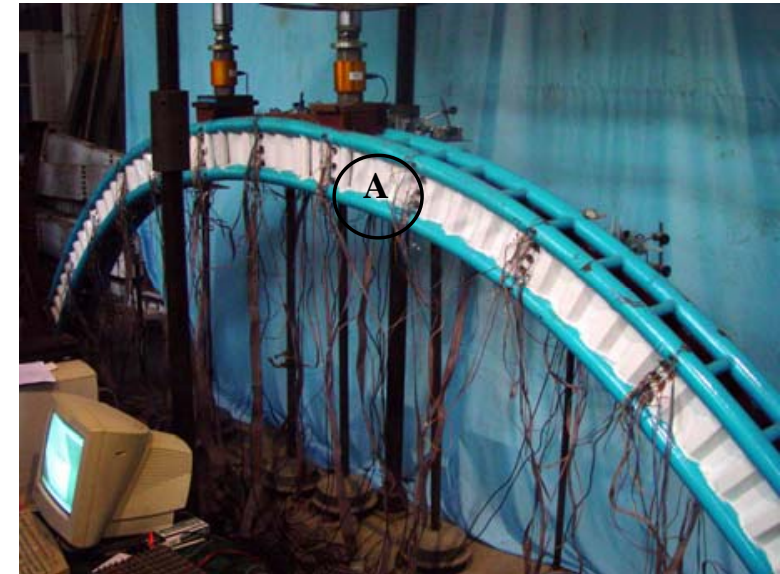

(a) Overall failure mode

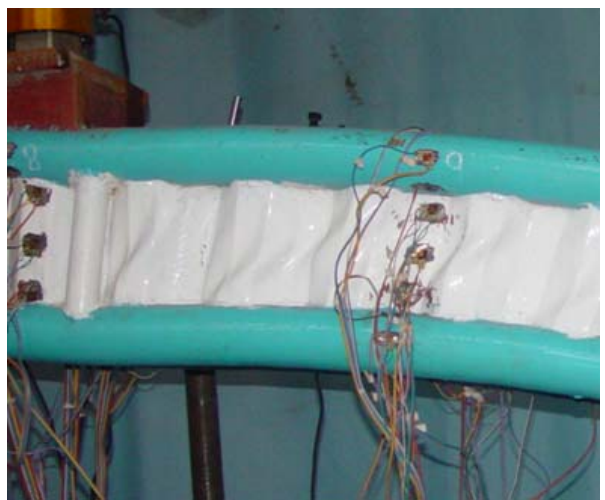

(b) Local buckling in region $\mathrm{A}$

Figure 4. View of ACSW-1 after Buckling Failure

The loading in the arch model ACSW-2 was applied at spans 2L/3 and 5L/6 simultaneously. No crack and wrinkle along the arch tube or buckling of the web was observed before the yielding of the chord steel tube. Failure in the arch was due to yielding of the tension chord, which started around loading positions and the arch springings. Figure 5 shows the deformed shape of ACSW-2 at the end of the test. As seen from the Figure, the global buckling and plastic deformation were concentrated at three positions due to the large bending moment in these regions, namely, $\mathrm{A}$ - between the left springing and $\mathrm{L} / 6, \mathrm{~B}$ - near the arch crown, and $\mathrm{C}$ - near the right springing. As a result, the stiffness and strength at the regions were significantly reduced. The buckling of CSWs became severe after the peak load.

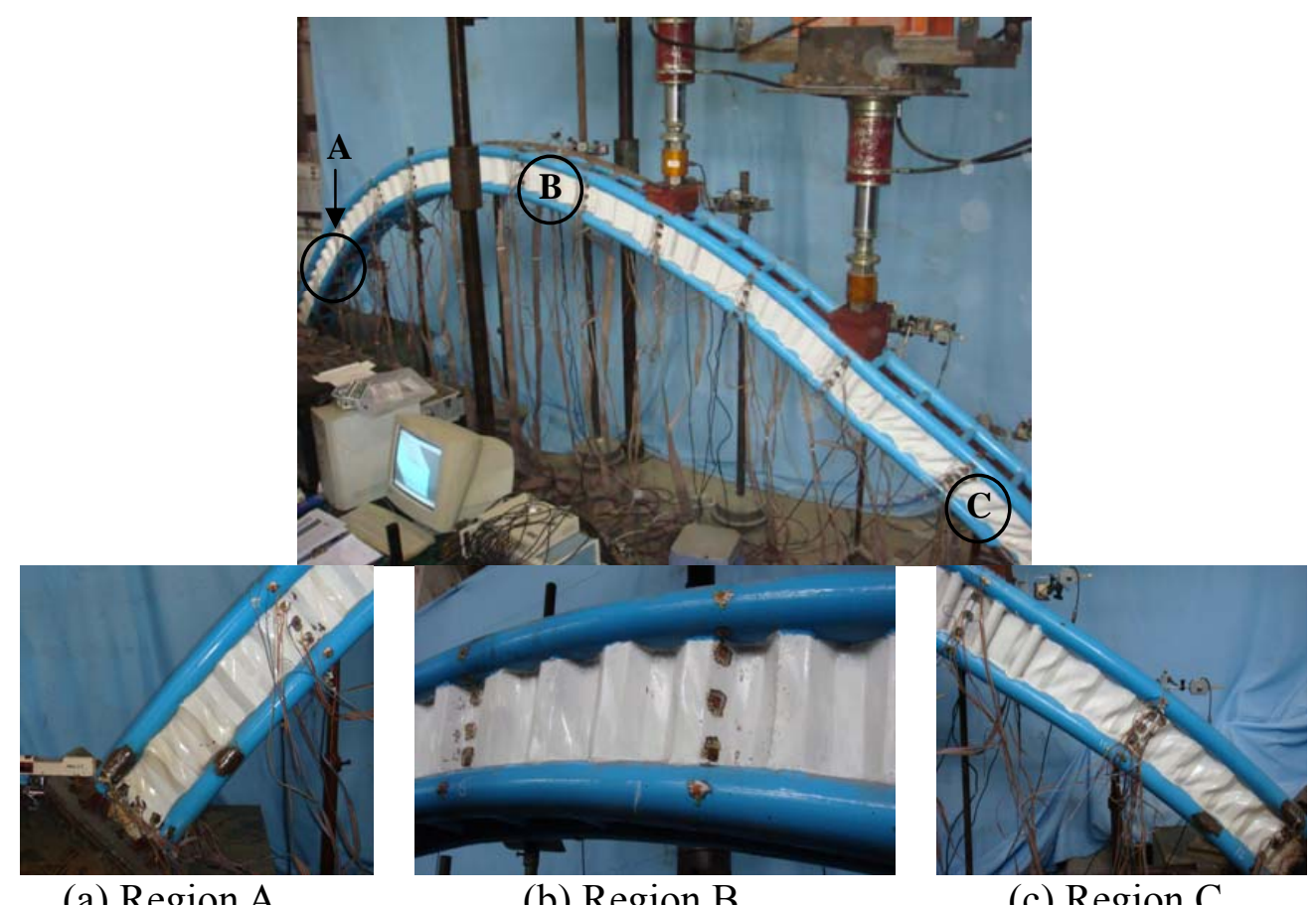

(a) Region A

(b) Region B

(c) Region C

Figure 5. View of ACSW-2 after Failure

For ACSW-3, the vertical load was applied simultaneously with the lateral load at the arch crown as shown in Figure 6. Both vertical deflections and the lateral deflections were symmetrical, and the maximum value occurred at the arch crown. In the later stage of the test, the lateral displacement 
developed rapidly, which shows that the stiffness of the arch nearly reached zero at this instance. Local buckling appeared at both springings only, and no obvious buckling could be observed at other sections.

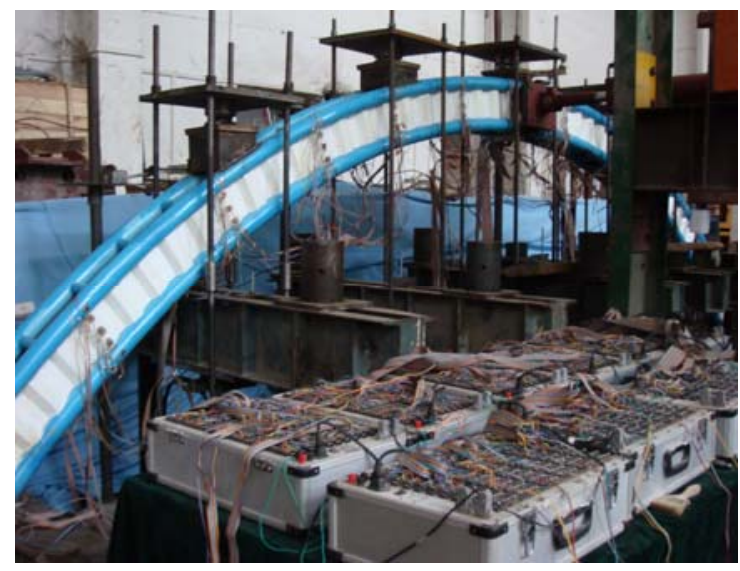

Figure 6. View of ACSW-3 in the Test

\section{$2.4 \quad$ Load-deflection Curves}

The vertical deflections of ACSW-1 at various testing stages are shown in Figure 7(a). Hereinafter, the loading magnitude refers to one single load $P$. The total vertical loads are $2 P, 2 P$, and $5 P$ for ACSW-1, ACSW-2, ACSW-3, respectively. As demonstrated in the Figure, the arch deflected symmetrically and the largest deflection occurred at the midspan. Two contraflexure points appeared near quarter spans. Figure 7(b) shows the load versus deflection response of the arch. Under the small load, the arch behaved elastically and linearly. After the load exceeded $200 \mathrm{kN}$, the deflection increased nonlinearly. The maximum deflection at the midspan was $45.3 \mathrm{~mm}$ under the failure load of $315 \mathrm{kN}$. During the test, the deflections from the contraflexure points to the arch springings were quite small even under the ultimate load.

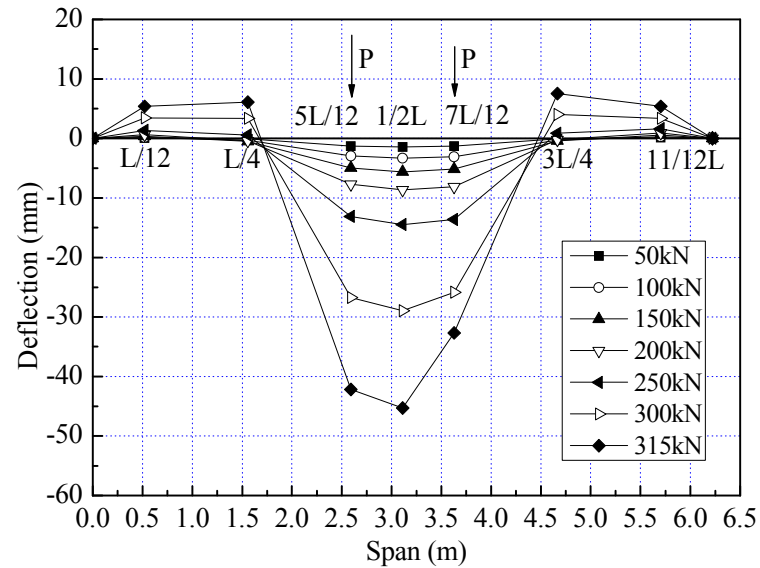

(a) Deflection of the arch

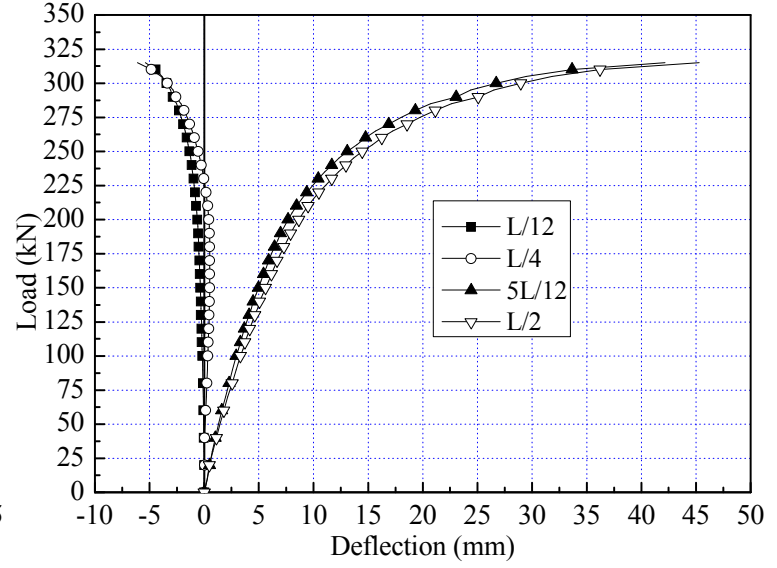

(b) Load-deflection curves

Figure 7. Load-deflection Curves of ACSW-1

The deflections along the arch ACSW-2 at different load levels are plotted in Figure 8(a), which shows that the deflection of the arch is generally asymmetric under the loading. Figure 8(b) shows the load versus deflection response. The deflection increases nonlinearly after the load is over 200 $\mathrm{kN}$. The maximum deflection occurred at $2 / 3$ of the span and amounted to $52.3 \mathrm{~mm}$ at the ultimate load of $280 \mathrm{kN}$. Comparison between Figures 7 and 8 shows that the ultimate load-carrying capacity of ACSW-1 is higher than that of ACSW-2. 


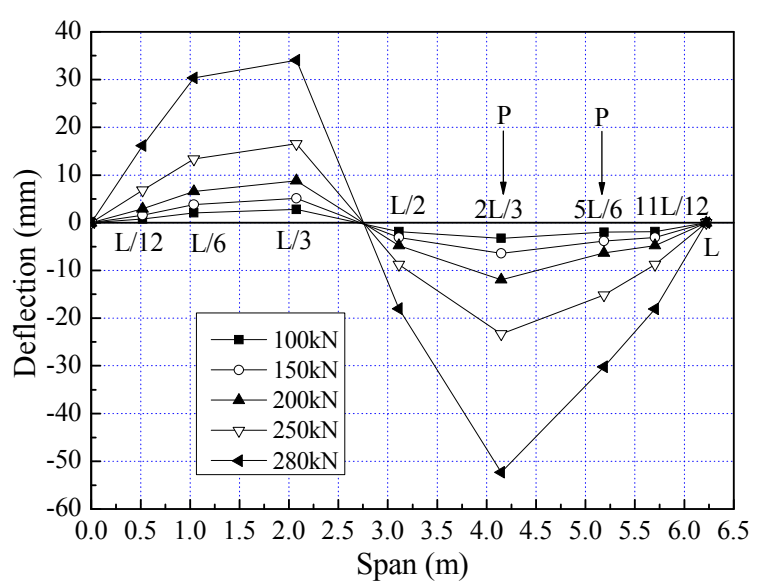

(a) Deflection along the arch

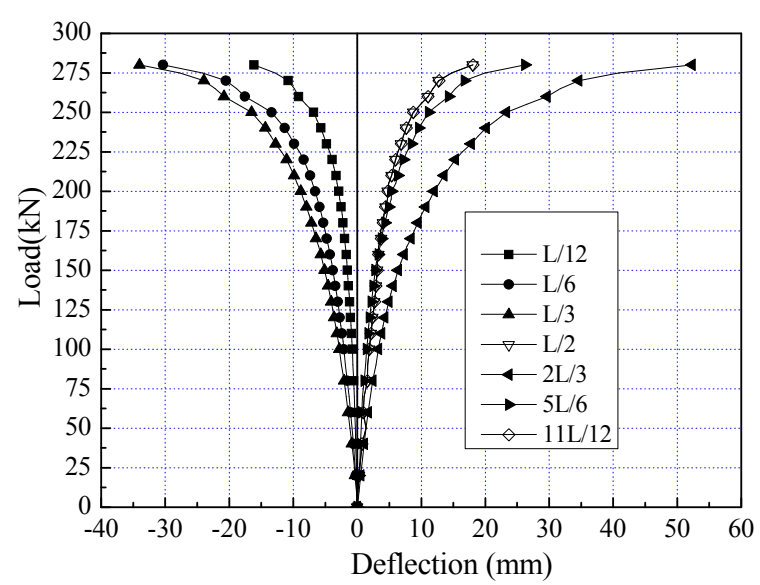

(b) Load-deflection curves

Figure 8. Load-deflection Curves of ACSW-2

Figure 9 shows the deflection distribution of ACSW-3 at specified loading steps. From the beginning, the lateral deflection is much larger than the vertical deflection although the total vertical load $(5 P)$ is 50 times of the lateral load $(P / 10)$, indicating that the in-plane stiffness of the arch is significantly larger than the out-of-plane one.

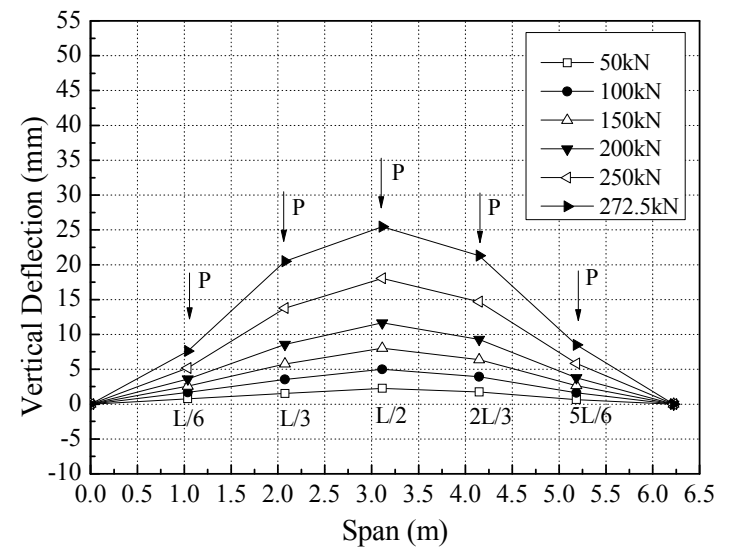

(a) Vertical deflection

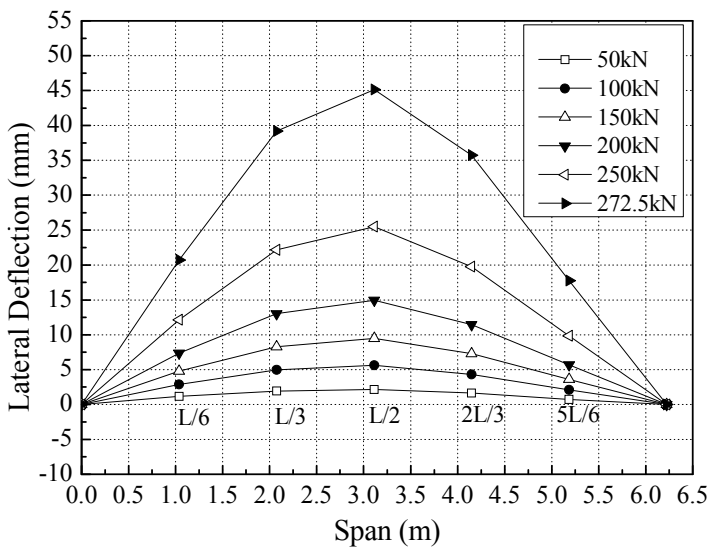

(b) Lateral deflection

Figure 9. Vertical and Lateral Deflection Curves of ACSW-3

The load-deflection relationship of ACSW-3 is shown in Figure 10. The slope of the curve in Figure 10 (a) is much larger than the curve in Figure 10(b). Loads refer to the vertical load $P$. The lateral deflection has little effect on the vertical one because the interaction between the out-of-plane and in-plane deflections is not obvious at the beginning. When the lateral load increases to some extent (about $P=170 \mathrm{kN}$ ), the increment of the in-plane and out-of-plane deflections develop rapidly, mostly at the midspan section. The lateral deflection is larger than the vertical deflection in the subsequent loading steps. Therefore, the failure mode of the arch is controlled by the lateral deformation. After $P=250 \mathrm{kN}$, the load vs. vertical deflection enters the nonlinear stage and reaches the ultimate load at $P=272.5 \mathrm{kN}$. Both the out-of-plane and in-plane deflections show a tendency to become fairly large as the vertical load increases and the collapse exhibits a complicated spatial behavior. 


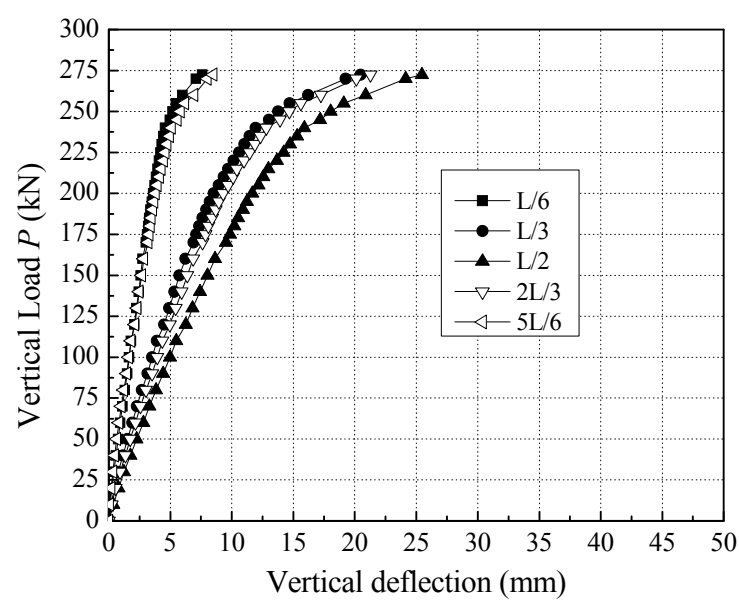

(a) Vertical deflection

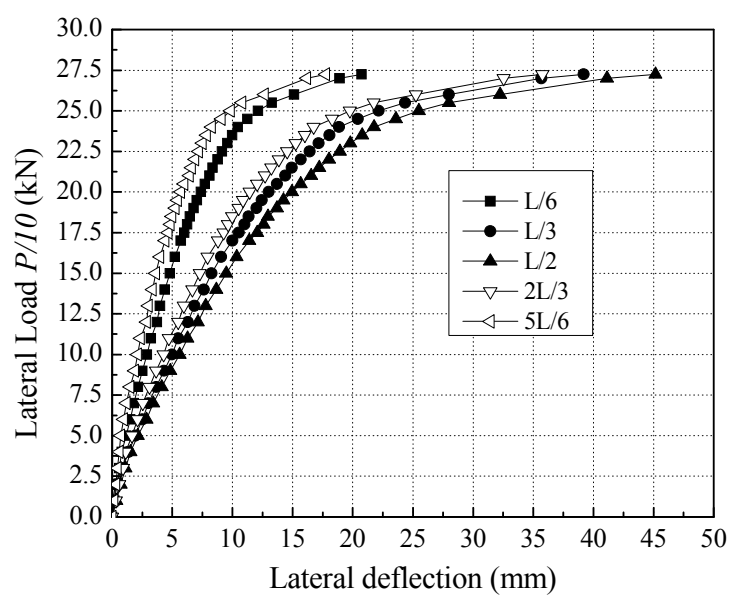

(b) Lateral deflection

Figure 10. Load-deflection Curves of ACSW-3

\subsection{Strain Responses}

\subsubsection{Strain in Chords}

The longitudinal strain distribution of the chords was measured by strain gauges (points 1 and 4 in Figure 3) on the top and bottom chords of ACSW-1 and ACSW-2. The results of ACSW-1 at various testing stages are plotted in Figure 11, in which the positive value denotes tension, negative value denotes compression, and the dotted line refers to the yield strain of steel $(1626 \mu \varepsilon)$. The strain distribution in the arch is nearly symmetric about the midspan, which confirms that the arch is essentially loaded symmetrically at each step with little eccentricity. At the top chord, the strains at the quarter span and springings increase rapidly after the load reaches $200 \mathrm{kN}$, and then exceed the yield strain when failure occurs, whereas other portions remain below the yield strain for all cases. The strain of the bottom chord is larger than that of the top chord, and the bottom chord yields over a large range after the loading reaches $250 \mathrm{kN}$, as shown in Figure 11(b). The strain of the chords develops quickly after the yielding occurs at the quarter spans, which indicates that the yielding of the tube members is the primary cause of the failure of the CFST-CSW arch.

The longitudinal strains of the arch chords for ACSW-2 are illustrated in Figure 12. Strains of many cross-sections of the tubes have reached the yield strain under the ultimate loading. The strain of the top chord develops rapidly after load of $200 \mathrm{kN}$, with the maximum values in tension and compression located at spans $\mathrm{L} / 4$ and $3 \mathrm{~L} / 4$, respectively. The maximum values in compression and tension of the bottom chord are located at spans $\mathrm{L} / 3$ and $2 \mathrm{~L} / 3$, respectively. For both top and bottom chords, the largest strains occur at the springings. 


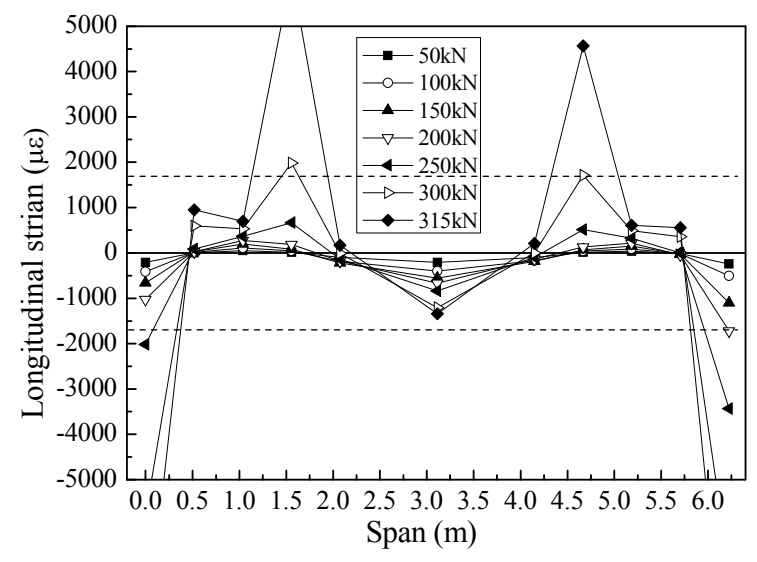

(a) Top chord (point 1)

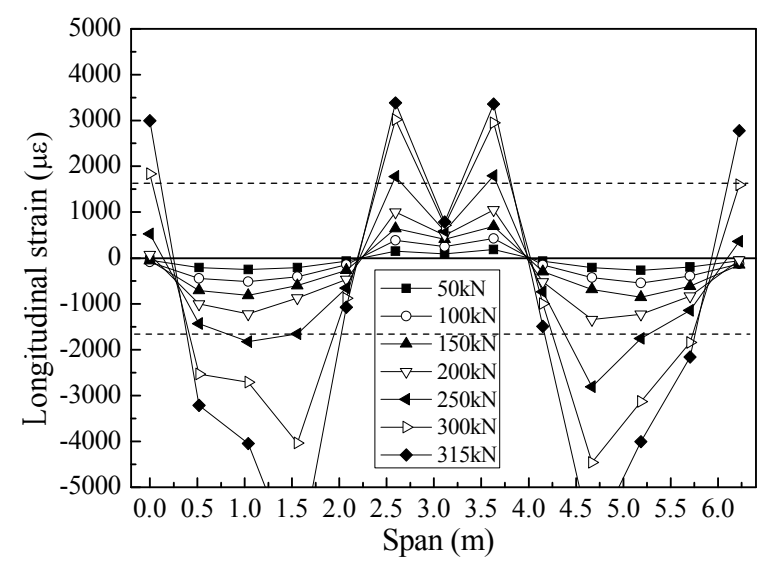

(b) Bottom chord (point 4)

Figure 11. Distribution of Strain in Chords of ACSW-1

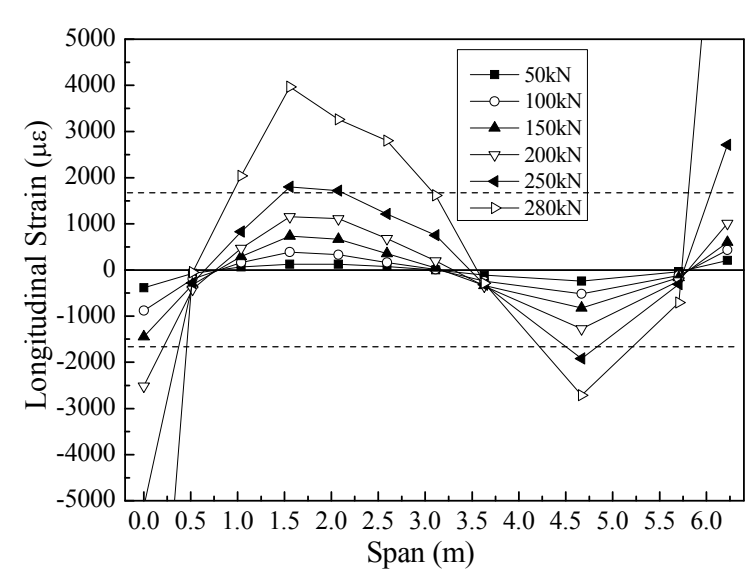

(a) Top chord (point 1)

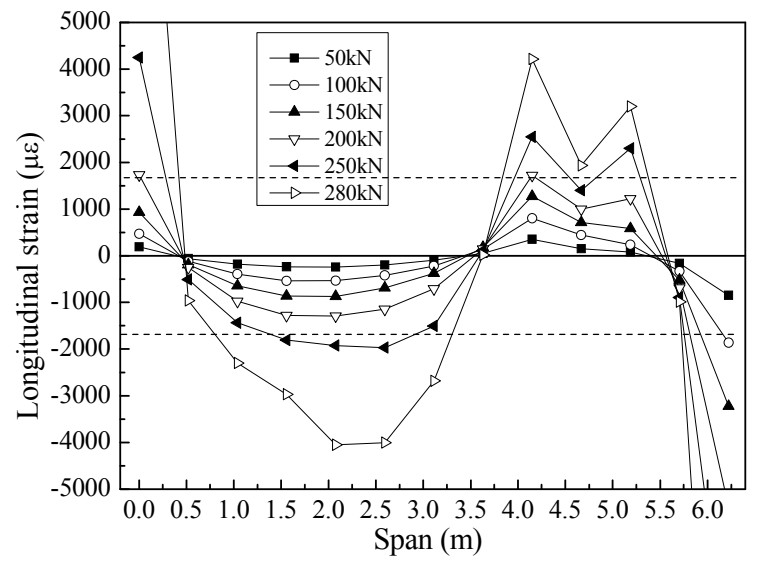

(b) Bottom chord (point 4)

Figure 12. Distribution of Strain in Chords of ACSW-2

For ACSW-3, the longitudinal strain distribution of the chords are illustrated in Figures 13 and 14. The strain distribution of the arch is almost symmetrical for most loading steps before reaching the failure load. During the test, most sections of the arch are in compression, except at the mid-span of the bottom chord (point 4).

The relationship between the longitudinal strain and applied load is plotted in Figure 15. The curves experience linear and nonlinear phases nearly in the same way. When the load increases to $250 \mathrm{kN}$, the strain in the bottom chord reverses direction, indicating the occurrence of stress redistribution. 


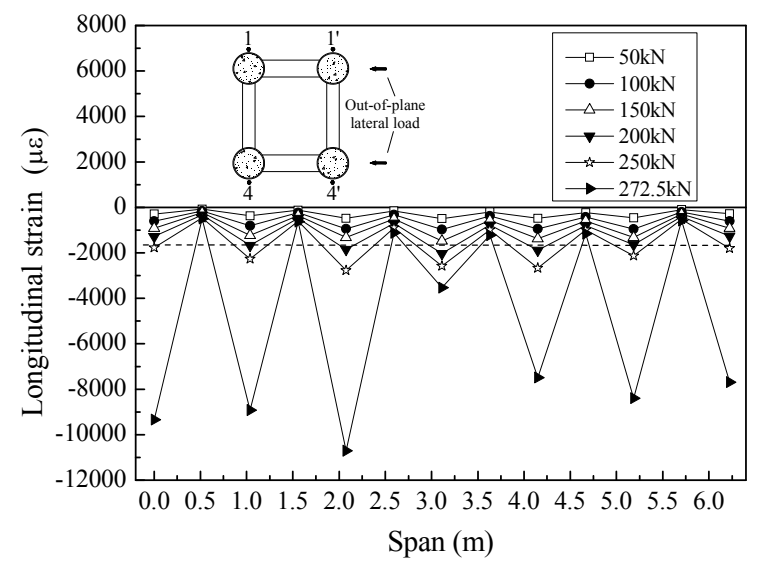

(a) Top chord (point 1)

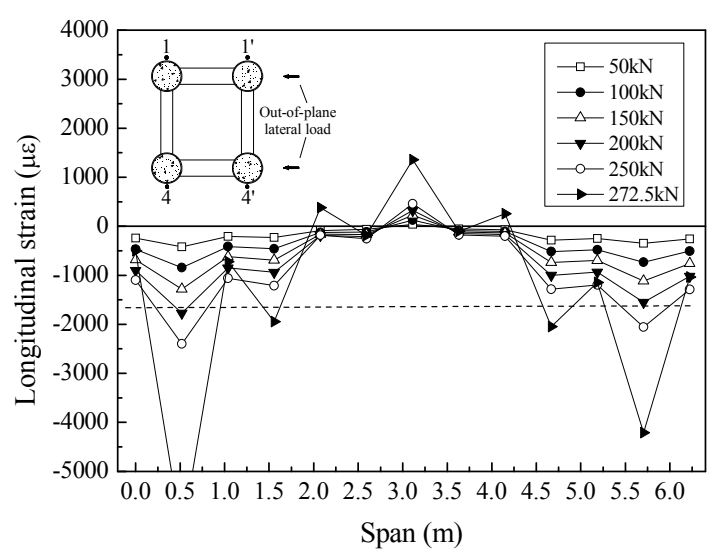

(b) Bottom chord (point 4)

Figure 13. Distribution of Longitudinal Strain at the Chords (Points 1 and 4)

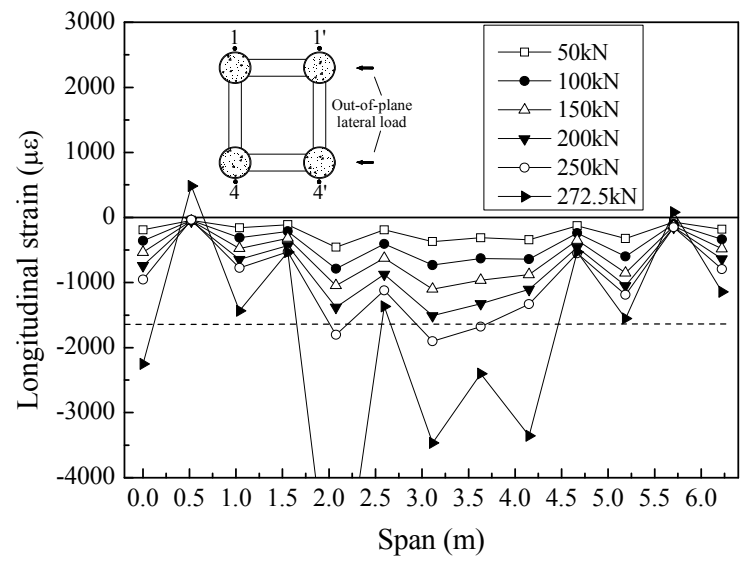

(a) Top chord (point 1')

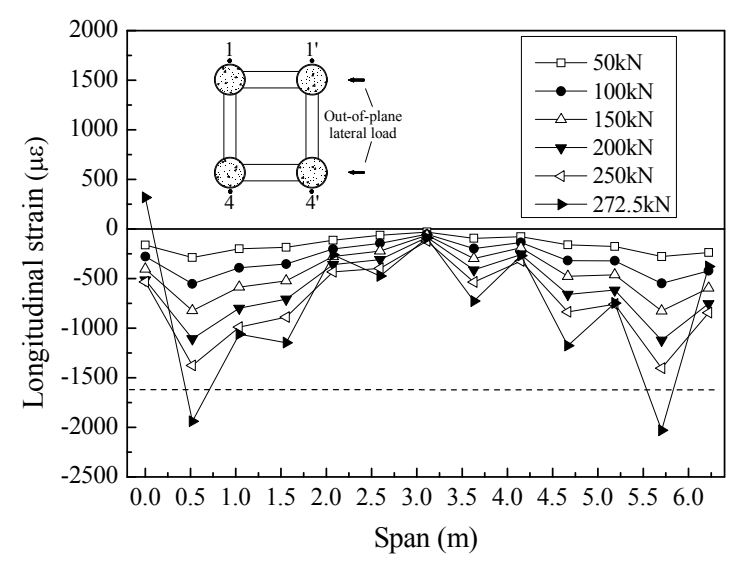

(b) Bottom chord (point 4')

Figure 14. Distribution of Longitudinal Strain at the Chords (Points 1' and 4')

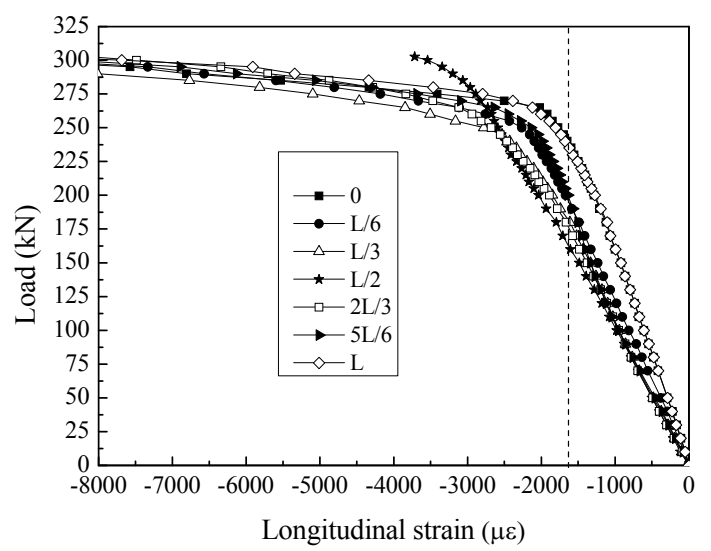

(a) Top chord (point 1)

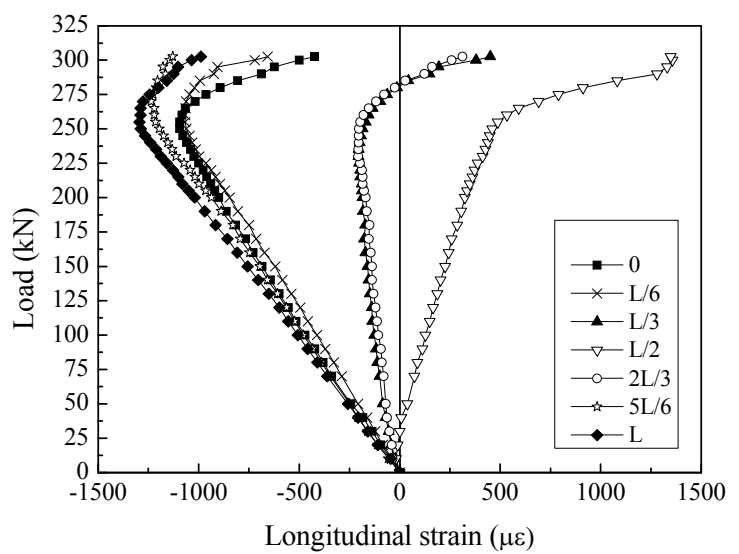

(b) Bottom chord (point 4)

Figure 15. Load-strain Curves of the Chords (Points 1 and 4) 


\subsubsection{Strain in Corrugated Steel Webs}

\section{Longitudinal Strain}

The longitudinal strains along the depth of the cross-sections were measured by strain gauges attached to the CFSTs and CSWs (points $1,2,5,7,8,9,6,3$, and 4 as shown in Figure 3). The results at two critical sections of ACSW-1 and ACSW-2 (i.e., left springing section and L/4 section) are shown in Figures 16 and 17, respectively. The longitudinal strains have an abrupt change at the junction of the CFST chords and CSWs, and the strains of the webs are generally much smaller than those of the chords, which is similar to the strain distribution in CFST-CSW girders [18] and columns [19]. Moreover, the result indicates that the contribution of the corrugated web to the compression and moment carrying capacity of the arch is lower than that of the CFST chord, and the ultimate load heavily depends on the chord yielding.

The longitudinal strains in the web at left springing and L/4 sections increase significantly after the applied load exceeds $250 \mathrm{kN}$, indicating the occurrence of the buckling in the web. This is because the yielding of the chord tubes results in the redistribution of the internal forces.

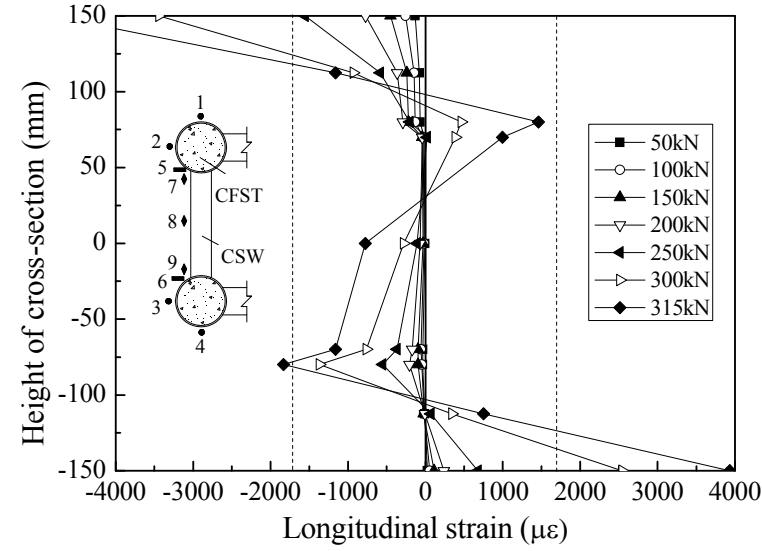

(a) At left springing

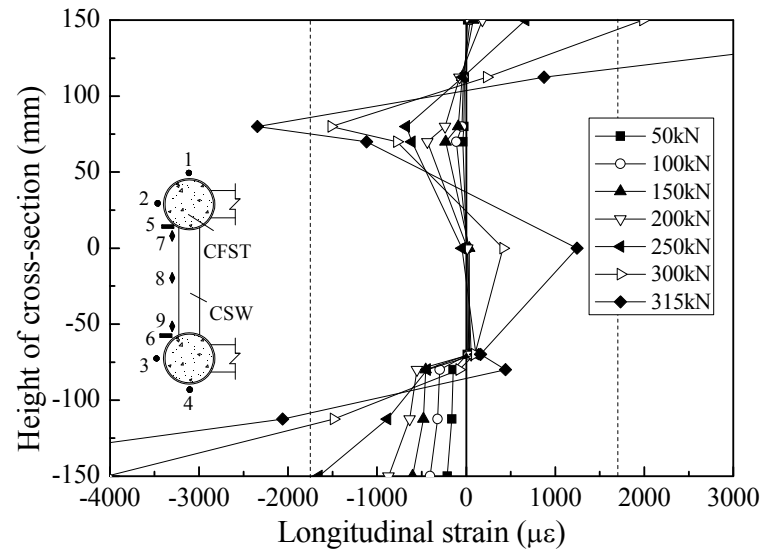

(b) At L/4 section

Figure 16. Distribution of Longitudinal Strain along the Depth of ACSW-1

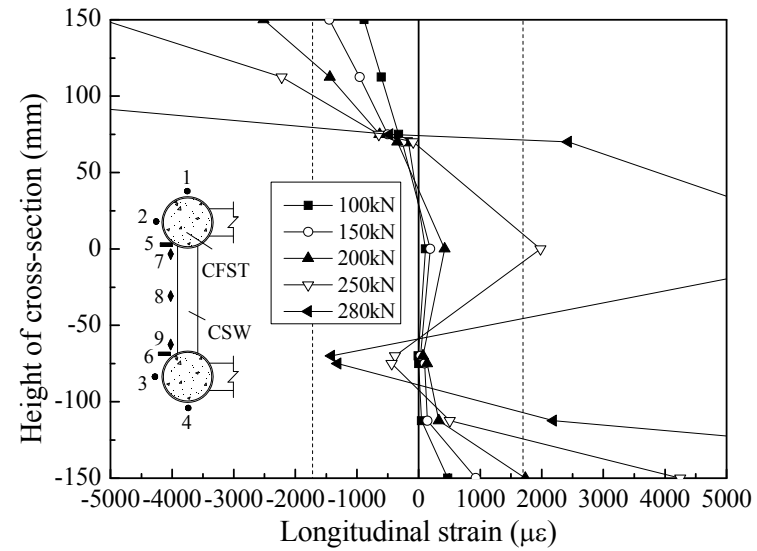

(a) At left springing

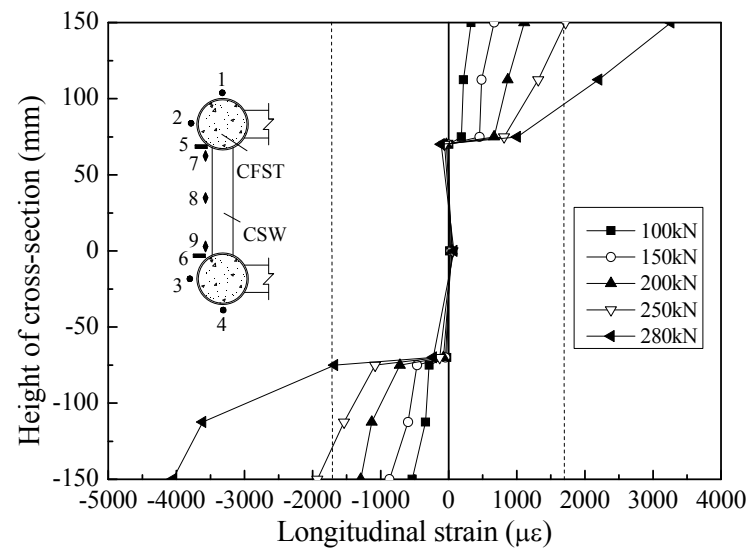

(b) At L/4 section

Figure 17. Distribution of Longitudinal Strain along the Depth of ACSW-2 
Figures 18 and 19 exhibit the longitudinal strain distribution along the depth of the two critical cross-sections (left springing section and L/3 section) of ACSW-3. Similarly, the longitudinal strains of the CSWs are quite small before yielding. The internal forces in the section are redistributed when the steel tubes in the bottom and top chords yield, causing the strains of the CSWs at the springing to increase beyond the yielding strain. However, the strains of the CSWs at other sections are still within their elastic strain even under the failure load, which demonstrates that the contribution of the corrugated web to the ultimate load capacity of the arch under the in-plane and out-of-plane loadings is negligible, and the ultimate load mainly relies on the chord yielding. In addition, Figures 18 and 19 show that the longitudinal strains along the depth of cross sections do not satisfy the plane section assumption.

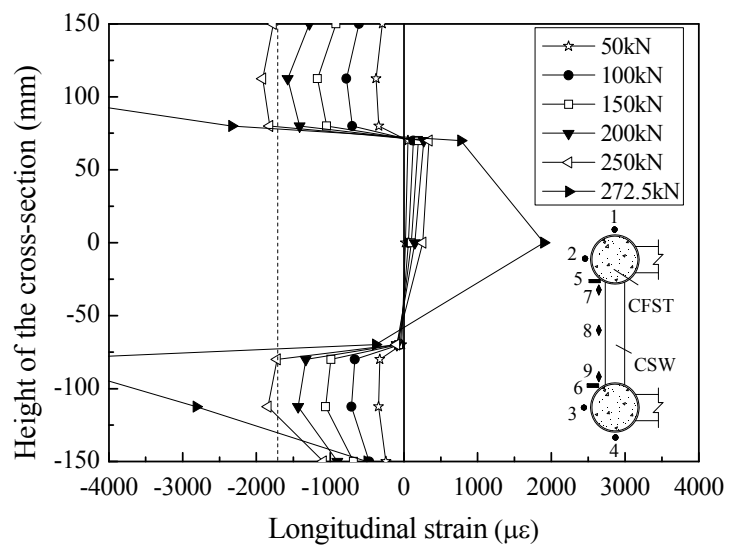

(a) At left springing

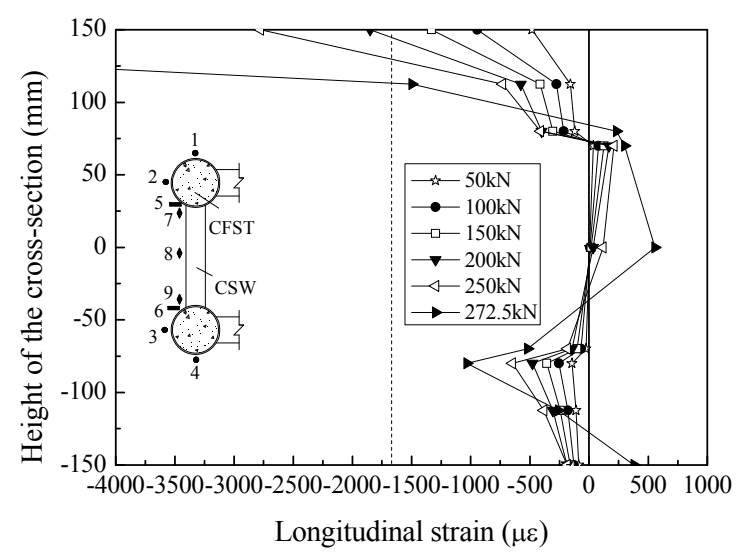

(b) At L/3 section

Figure 18. Distribution of Longitudinal Strain along the Depth of ACSW-3 without the Lateral Load

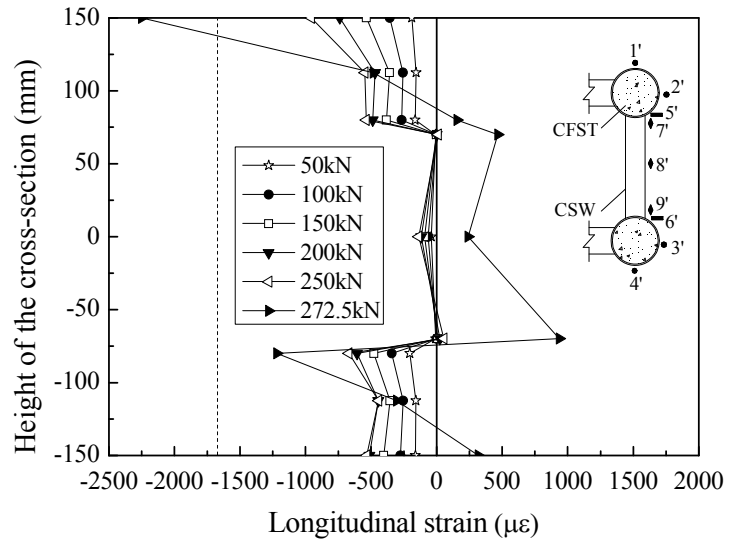

(a) At left springing

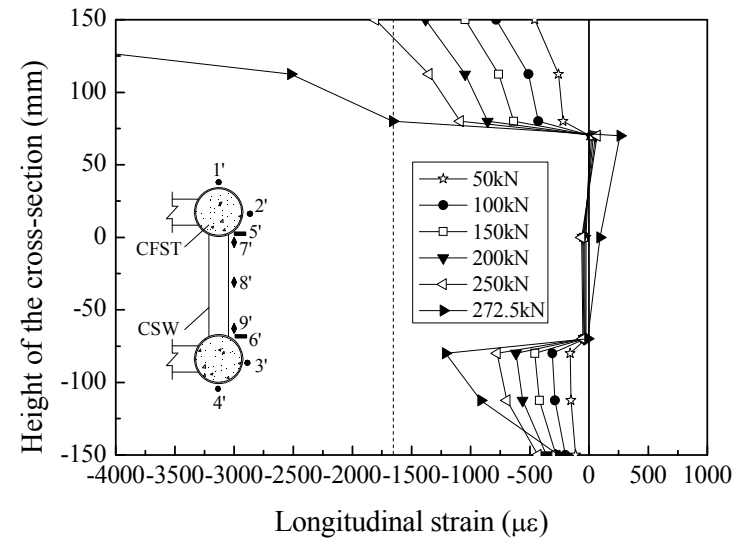

(b) At L/3 section

Figure 19. Distribution of Longitudinal Strain along the Depth of ACSW-3 subjected to the Lateral Load

\section{Shear Strain}

The shear strains in the CSWs were obtained from the measurement of the strain rosettes installed on the webs.

The shear strains at mid-height of the web (point 8 in Figure 3) located at left springing versus the loading applied are plotted in Figure 20. The three arches have similar shear strains at the elastic stage. After chord yielding occurs, the webs experience very large shear strains. 


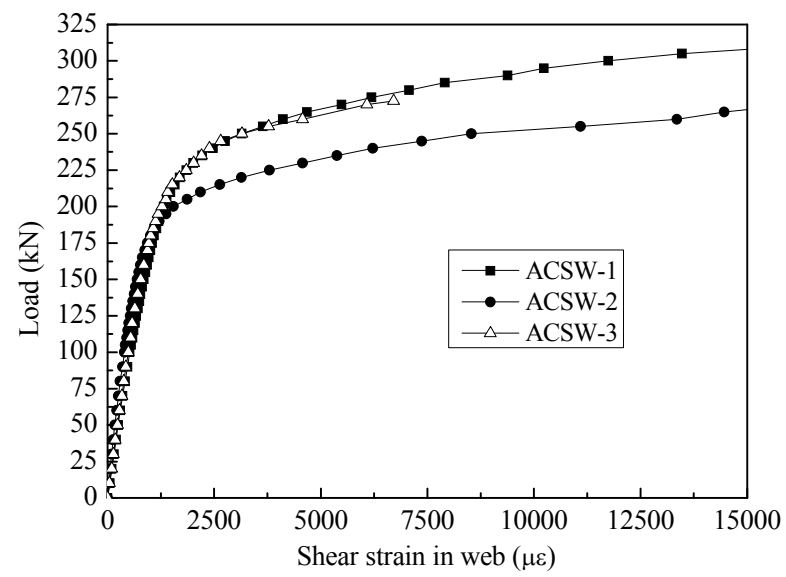

Figure 20. Load-shear Strain Curves at the Left Springing of the Arches (Point 8)

Figure 21 shows the shear strain distribution along the web height of the three arch models. In the elastic range, the shear strains along the height of the web are similar. In the plastic stage, the shear strain at the mid-height of the web increases significantly. Reminding that the webs have low longitudinal strains, one can conclude that the bending moment and compression of the section are mainly resisted by the top and bottom chords, and the shear forces are mainly carried by the CSWs. The top and bottom chords can work together because of the high shear resistance of the CSWs, which is one of main characteristics of the new CSFT-CSW structure.

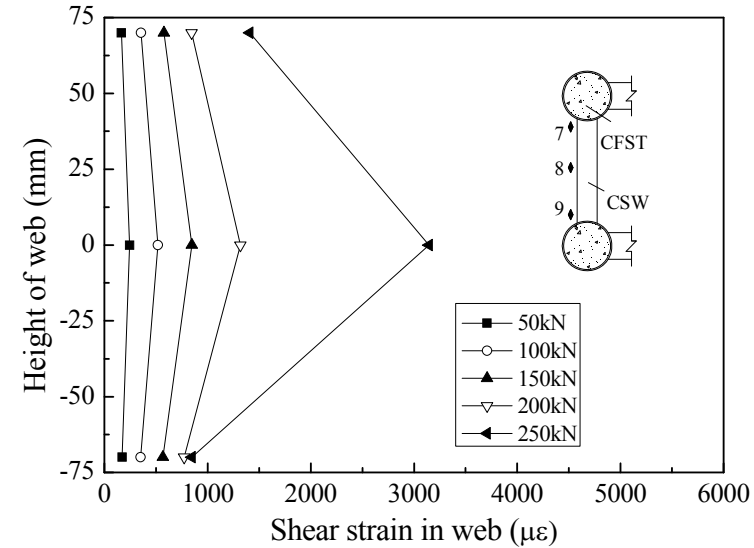

(a) ACSW-1

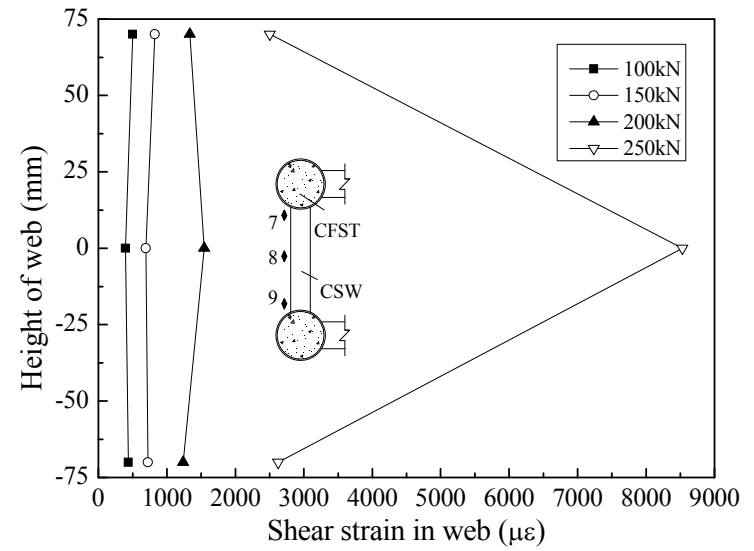

(b) ACSW-2

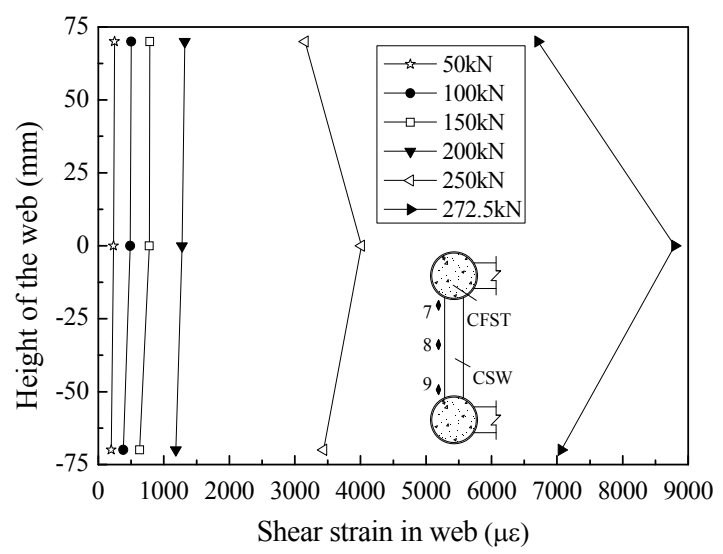

(c) ACSW-3

Figure 21. Distribution of Shear Strain along the Height of Web at Left Springing 


\section{COMPARISON BETWEEN CFST-CSW ARCH AND RC-CSW ARCH}

Most arch bridges employ CFST truss ribs or RC components. The previous analysis shows that the proposed new CFST-CSW arches can fully utilize the merits of the high compression strength of CFST chords and the enhanced shear resistance of CSWs, and consequently develop a significant plastic deformation. Researchers have also investigated the alternatives to heavy-weight concrete arches. For example, Huang [20] carried out tests on a RC arch model with CSW (briefly as RC-CSW arch), which aimed to reduce the weight of RC webs. This RC arch model was designed with similar load-carrying capacity and safety margin as the ACSW-2. Therefore, they have similar span, rise, rise-span ratio, cross-section, and material characteristics. The loading steps and sensor installation of the RC-CSW arch are similar to those of ACSW-2. The two arch models are compared in the following sections to further verify the effectiveness of the CFST-CSW arches.

\subsection{Experiment of the RC-CSW Arch [20]}

The RC-CSW arch model [20] is shown in Figure 22. The arch has a span of $6.252 \mathrm{~m}$ and a rise of $1.557 \mathrm{~m}$. The top and bottom flanges were made of reinforced concrete and connected by two 2.8 $\mathrm{mm}$ thick CSWs. The CSWs used in the $\mathrm{RC}$ arch were a little bit thicker than those used in the CFST arch to avoid local buckling of the CSWs as the RC arch was much heavier. The average yield stress of the steel was $380 \mathrm{MPa}$, and the average ultimate strength was $500 \mathrm{MPa}$. The tested Young's elastic modulus of steel was $206 \mathrm{GPa}$. The average ultimate strength of concrete was 41 $\mathrm{MPa}$ with the Young's modulus of $30 \mathrm{GPa}$. The arch model was subjected to asymmetrical loadings at $2 \mathrm{~L} / 3$ and $5 \mathrm{~L} / 6$ sections, the same loading condition as ACSW-2. In order to compare the effectiveness of use of material for the two types of structure, the equivalent areas as steel section according to the principle of composite cross-section equivalent stiffness are compared, as shown in Table 1. For brevity, only the load-deflection and failure mode of the two models are compared.

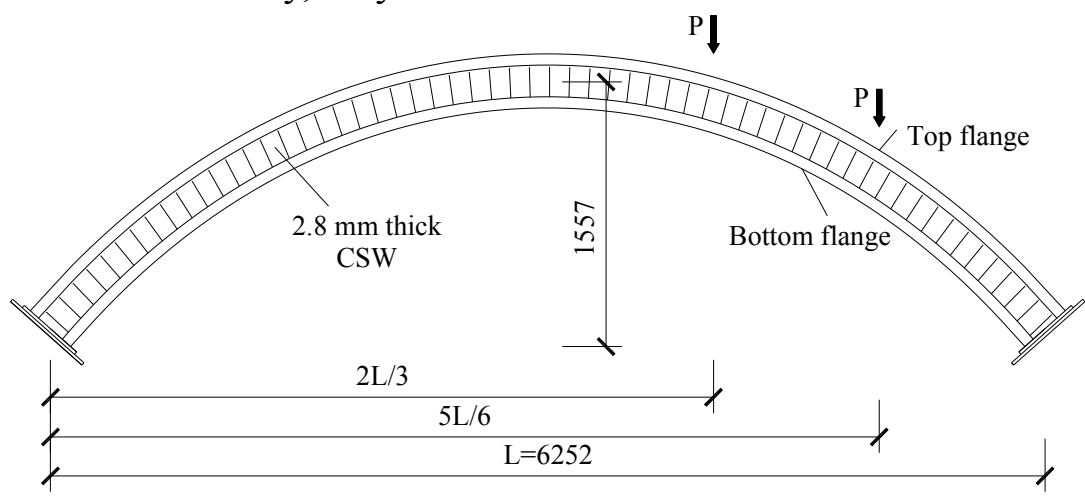

(a) Elevation

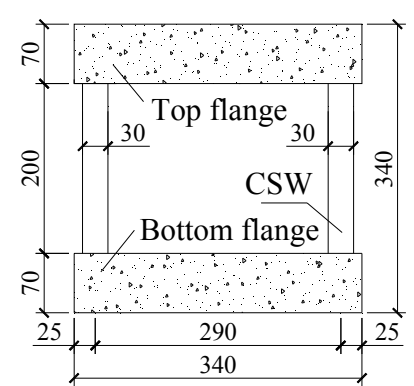

(b) Cross-section

Figure 22. The RC Arch with CSW (Unit: mm)

\subsection{Ultimate Load and Ductility}

The load-deflection curves at the loading position ( $2 \mathrm{~L} / 3$ section) of the two models are compared in Figure 23. The ultimate loads of the two arches are $304 \mathrm{kN}$ for RC-CSW arch and $280 \mathrm{kN}$ for ACSW-2. The RC-CSW arch has the ultimate load capacity 9\% larger than ACSW-2 but its equivalent area as steel section and mass per unit length is more than double. Therefore, it may be concluded that the CFST-CSW arch has a relatively higher ultimate load-carrying capacity because the resistance of the RC-CSW arch is limited by the development of cracking, which results in the formation of plastic hinges. Moreover, the deflection of the RC-CSW arch is only about $70 \%$ of ACSW-2 at the ultimate state, indicating that the CFST-CSW arch has much higher deformation capacity and better ductility than the RC-CSW arch. 


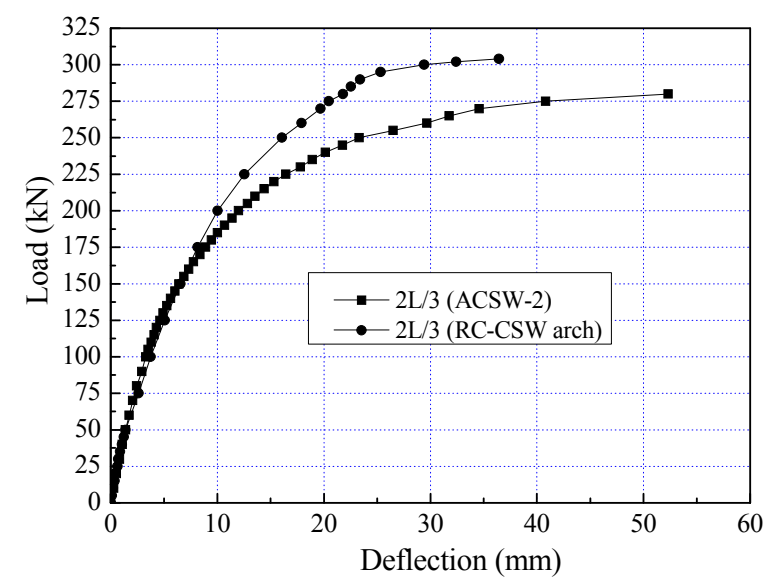

Figure 23. Load-deflection Curves at 2L/3 for Both Arches

Table 1. Comparison of Cross Section Properties and Ultimate Load of ACSW-2 and RC-CSW Arch

\begin{tabular}{ccccc}
\hline Item & $\begin{array}{c}\text { Equivalent area } \\
\text { as steel section } \\
\left(\mathrm{m}^{2}\right)\end{array}$ & $\begin{array}{c}\text { Mass per unit } \\
\text { length } \\
(\mathrm{kg} / \mathrm{m})\end{array}$ & $\begin{array}{c}\text { Maximum } \\
\text { deflection at } \\
2 \mathrm{~L} / 3 \\
(\mathrm{~mm})\end{array}$ & $\begin{array}{c}\text { Ultimate } \\
\text { load } \\
(\mathrm{kN})\end{array}$ \\
\hline RC-CSW arch & $8.79 \times 10^{-3}$ & 123 & 36.4 & 304 \\
\hline ACSW-2 & $4.35 \times 10^{-3}$ & 56 & 52.3 & 280 \\
\hline $\begin{array}{c}\text { Ratio between the two } \\
\text { arches }\end{array}$ & 2.02 & 2.19 & 0.696 & 1.09 \\
\hline
\end{tabular}

\subsection{Cracking and Failure Mode}

For the RC-CSW arch, extensive cracks occurred at the $2 \mathrm{~L} / 3$ section of the bottom flange under ultimate load as shown in Figure 24(a). Cracks also occurred at L/4 section of the top flange as shown in Figure 24(b). Due to the formation of a plastic hinge around this cracked area, the deflection at this area increased about $10 \mathrm{~mm}$ at nearly constant load level. Failure of the arch was characterized by the yielding of steel reinforcement in the maximum moment region, followed by concrete crushing on the top flange near the loading position. Although the internal force tended to close cracks after unloading, some of the cracks did not close completely due to the large plastic deformation.

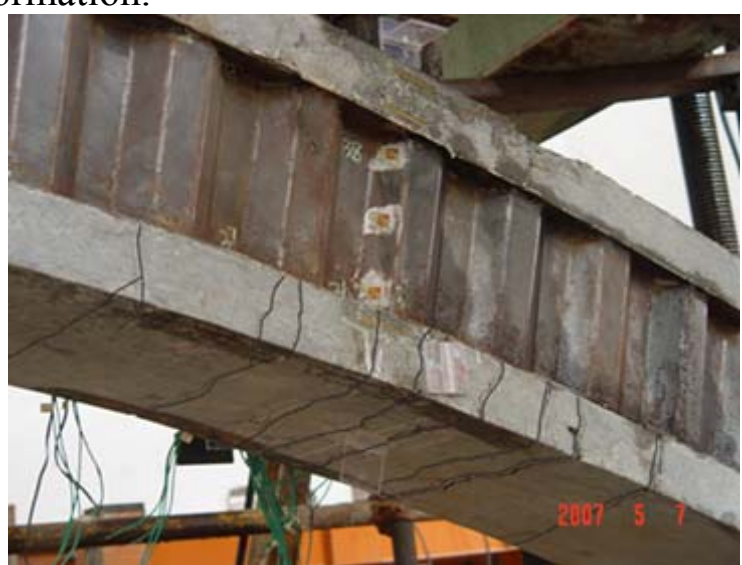

(a) At 2L/3 section (Loading position)

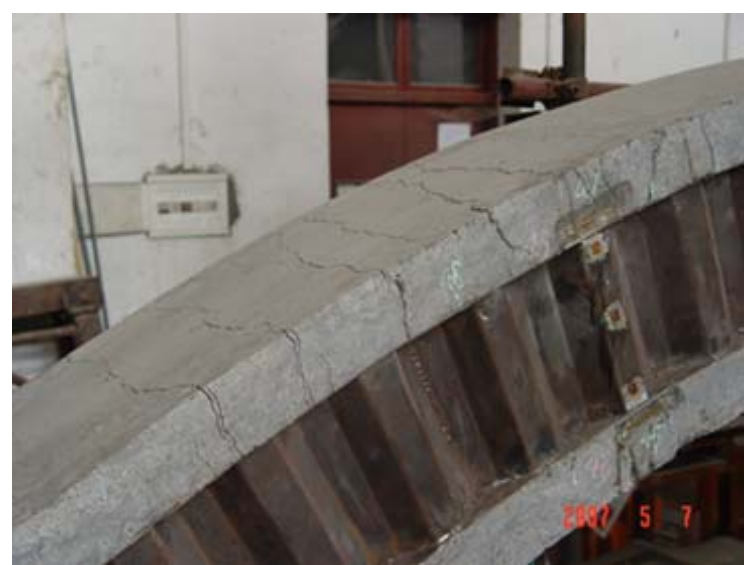

(b) At L/4 section

Figure 24. Failure Mode of the RC-CSW 
Although both arches failed at the 2L/3 loading section, no distinct plastic hinges were observed during the experiment of ACSW-2, whereas the RC-CSW arch failed with several plastic hinges. Therefore, the plastic hinge method for calculating ultimate load of RC arch should not be employed in the CFST-CSW arch.

\section{CONCLUSIONS AND DISCUSSIONS}

This paper investigates the ultimate load-carrying capacity of CFST-CSW arches subjected to in-plane and out-of-plane loadings. The deflections and strains under different loadings were measured. The ultimate load and failure mode of the CFST-CSW and RC-CSW arches were compared. Conclusions can be drawn as follows:

1. The ultimate load-carrying capacity of the CFST-CSW arch under the symmetric loading is higher than under the asymmetric one.

2. The arch under in-plane and out-of-plane loadings simultaneously exhibits a larger lateral deflection and lower ultimate load compared with the in-plane loading. The design of such arches needs to give special attention to the out-of-plane stability.

3. Before leading to the buckling of the CSWs, the arches fail after most sections of the chords yield whether or not they are subjected to the symmetric or asymmetric loadings.

4. In CFST-CSW arches, the potential advantages of both the high compression strength of CFST chords and enhanced shear resistance of CSWs are fully utilized.

5. The CFST-CSW arches can sustain large plastic deformation as well as relatively high load carrying capacity. The plastic hinge method for calculating the ultimate load of RC arches may not be suitable for CFST-CSW arches.

In order to develop the design method of CFST-CSW arches, a number of parameters such as cross-section configuration, geometric dimension (including cross-sectional size, span, rise, and so forth), material properties, and loading conditions need to be further studied. Moreover, finite element analysis should be performed to double check the detailed structural behaviours. In addition, simplified methods for the calculation of the ultimate load of CFST-CSW arches should be developed. These merit further investigations.

\section{ACKNOWLEDGMENT}

This research work has been conducted under Grant No. 50778043 of the National Natural Science Foundation of China and Grant No. 2011J05138 of the Natural Science Foundation Project of Fujian Province, China.

\section{REFERENCES}

[1] Zhao, X.L., Han, L.H. and Lu, H., "Concrete-filled Tubular Members and Connections", Taylor \& Francis, UK, 2010.

[2] Zhong, S.T., "The Development of Concrete Filled Steel Tubular Structures in China", Proceeding of 3th International Conference on Concrete Filled Steel Tubular Structures (including Composite Beams) ASCCS, Harbin, China, 1988, pp. 1-7. 
[3] Bradford, M.A., Loh, H.Y. and Uy, B., "Slenderness Limits for Filled Circular Steel Tubes" Journal of Constructional Steel Research, 2002, Vol. 58, No. 2, pp. 243-252.

[4] Roeder, C.W., Lehman, D.E. and Bishop, E., "Strength and Stiffness of Circular Concrete-filled Tubes”, Journal of Structural Engineering, ASCE, 2010, Vol. 136, No. 12, pp. 1545-1553.

[5] Pi, Y.L., Liu, C.Y., Bradford, M.A. and Zhang, S.M., "In-plane Strength of Concrete-filled Steel Tubular Circular Arches", Journal of Constructional Steel Research, 2012, Vol. 69, No. 1, pp. 77-94.

[6] Bode, H., "Columns of Steel Tubular Sections Filled with Concrete: Design and Application", Acier-Stahl-Steel, 1976, 11-12, pp. 388-393.

[7] Chen, B.C. and Wang, T.L., "Overview of Concrete Filled Steel Tube Arch Bridges in China", Practice Periodical on Structural Design and Construction, ASCE, 2009, Vol. 14, No. 2, pp. 70-80.

[8] Mu, T.M., Fan, B.K., Zheng, X.F., Zheng, Y.H. and Xie, B.Z., "Wuxia Yangtze-River Bridge in Wushan, China", Proceeding of 5th International Conference on Arch Bridge, Madeira, Portugal, 2007, pp. 911-918.

[9] Ou, Z.J., Chen, B.C., Hsieh, K.H., Halling, M.W. and Barr, P.J., "Experimental and Analytical Investigation of Concrete Filled Steel Tubular Columns", Journal of Structural Engineering, ACSE, 2011, Vol. 137, No. 6, pp. 635-645.

[10] Chen, B.C. and Huang, W.J., "Experimental Research on Ultimate Load Carrying Capacity of Truss Girders Made with Circular Tubes", Journal of Building Structures, 2007, Vol. 28, No. 3, pp. 31-36 (in Chinese).

[11] Elgaaly, M., Hamilton, R.W. and Seshadri, A., "Shear Strength of Beams with Corrugated Webs", Journal of Structural Engineering, ASCE, 1996, Vol. 122, No. 4, pp. 390-398.

[12] Johnson, R.P. and Cafolla, J., "Corrugated Webs in Plate Girders for Bridges", Proceedings of the Institution of Civil Engineers, Structures and buildings, 1997, Vol. 122, No. 2, pp. 157-164.

[13] Chan, C.L., Khalid, Y.A., Sahari, B.B. and Hamouda, A.M.S., "Finite Element Analysis of Corrugated Web Beams under Bending", Journal of Constructional Steel Research, 2002, Vol. 58, pp.1391-1406.

[14] Li, H.J., Ye, J.S., Wan, S., Qian, P.S. and Jiang, Z.G., "Experimental Research on Prestressed Concrete Box Girder with Corrugated Steel Webs", China Journal of Highway and Transport, 2004, Vol. 17, No. 4, pp. 31-36 (in Chinese).

[15] Brozzetti, J., "Design Development of Steel-concrete Composite Bridges in France", Journal of Constructional Steel Research, 2000, Vol. 55, No. 1, pp. 229-243.

[16] Chen, B.C. and Wang, Y.Y., "Concrete Arch with Corrugated Web-A New Approach for Super-long Span Arch Bridge", Proceeding of 5th International Conference on Arch Bridge, Madeira, Portugal, 2007, pp. 807-814.

[17] Wei, J.G., Huang, Q.W. and Chen, B.C., "Trial Design of Arch Bridge of Composite Box Section with Steel Web-concrete Flange", Frontiers of Architecture Civil Engineering in China, 2010, Vol. 4, No. 3, pp. 370-375.

[18] Gao, J. and Chen, B.C., "Experimental Research on Beams with Tubular Chords and Corrugated Steel Web", Proceeding of 12th International Symposium on Tubular Structures, Shanghai, China, 2008, pp. 563-570.

[19] Gao, J., and Chen, B.C., "Experimental Research on Concrete Filled Steel Tubular Columns with Trapezoidally Corrugated Steel Webs", Proceeding of 10th International Symposium on Structural Engineering for Young Experts, Changsha, China, 2008, pp. 611-616.

[20] Huang, Q.W., "Research on In-plane Mechanical Behaviors of Concrete Arch with Steel Webs", PhD Thesis, Fuzhou University, China, 2009. (in Chinese) 